\title{
Relações entre volume e massa da madeira e casca de jurema-preta (Mimosa tenuiflora)
}

Tatiane K. B. de Azevêdo ${ }^{1}$, Juarez B. Paes ${ }^{2}$, Leandro Calegari ${ }^{3}$ \& José W. B. do Nascimento ${ }^{4}$

\footnotetext{
1 Universidade Federal Rural de Pernambuco, Programa de Pós-Graduação em Ciências Florestais, Rua Dom Manoel de Medeiros, s/n, Dois Irmãos, CEP 52171-900, RecifePE, Brasil. E-mail: tatianekellyengenheira@hotmail.com

2 Universidade Federal do Espírito Santo, Centro de Ciências Agrárias, Departamento de Ciências Florestais e da Madeira, Av. Gov. Lindemberg, 316, Centro, CEP 29550-000, Jerônimo Monteiro-ES, Brasil. Caixa Postal 16. E-mail: jbp2@uol.com.br

${ }^{3}$ Universidade Federal de Campina Grande, Centro de Saúde e Tecnologia Rural, Unidade Acadêmica de Eng. Florestal, Setor de Tecnologia de Produtos Florestais, Bairro Santa Cecília, CEP 58700-970, Patos-PB, Brasil. Caixa Postal 64. E-mail: calegari@cstr.ufcg.edu.br

${ }^{4}$ Universidade Federal de Campina Grande, Centro de Tecnologia e Recursos Naturais. Av. Aprígio Veloso, 882, Bodocongó, CEP 58109-725, Campina Grande-PB, Brasil. E-mail: wallace@deag.ufcg.edu.br
}

\section{RESUMO}

A jurema-preta (Mimosa tenuiflora) é uma espécie típica do semiárido brasileiro, utilizada com forrageira, fonte energética, cercas e com potencial para a produção de taninos vegetais. Porém há poucos estudos sobre as relações dendrométricas da espécie. Este estudo teve como objetivos avaliar o volume e a massa de madeira (lenha) e o volume e a massa de casca de jurema-preta e verificar sua variação nos períodos seco e chuvoso. Assim, foram coletadas, trimestralmente, em Santa Terezinha, Paraíba, 10 plantas de jurema-preta totalizando 40 plantas, e realizadas cubagens rigorosas da madeira com e sem casca, pesagens, determinação da umidade da madeira e casca e verificadas as relações entre os parâmetros dendrométricos. Observou-se que o volume e a massa de madeira não estão relacionados com o volume nem com a massa de casca. Com relação à umidade da madeira e da casca, observou-se que nos meses de dezembro de 2008 (início do período chuvoso) e abril de 2009 (final de período chuvoso) ocorreu maior umidade; nos meses de dezembro de 2008 e abril de 2009 também se observou maior percentual de folhas verdes nas copas das árvores, em função da ocorrência de chuva durante a coleta do material.

Palavras-chave: dendrometria, fenologia, inventário florestal

\section{Relationship between volume and mass of wood and bark in Mimosa tenuiflora}

\begin{abstract}
The Mimosa tenuiflora is a species typical of the Brazilian semi-arid region, used as forage, energy source, fences and with potential for production of vegetable tannins. However, there are few studies on the relationships of dendrometric parameters of species. This study aimed to evaluate the volume and mass of wood (firewood) and the volume and mass of bark in Mimosa and verify their variation during the dry and rainy seasons. Thus, were collected, on a quarterly basis, in Santa Terezinha, Paraíba, Brazil, 10 plants of Mimosa tenuiflora, a total of 40 plants, and conducted strict cubic content of wood with and without bark, measurements, determination of moisture content of wood and bark and established relations between the dendrometric parameters. It was noted that the volume and mass of wood are not related to the volume and mass of bark. Moisture content in wood and bark showed that in the months of December 2008 (beginning of the rainy season) and April 2009 (the end of rainy season) was high. In the months of December 2008 and April 2009 higher percentage of green leaves in the trees was observed, due to the occurrence of rain during the collection of the material.
\end{abstract}

Key words: dendrometry, phenology, forest inventory 


\section{Introdução}

A Caatinga, vegetação do Semiarido brasileiro, ocorre em uma extensão territorial de aproximadamente $800.000 \mathrm{Km}^{2}$; apesar da abrangência, é um dos biomas menos estudados e protegidos dentre os biomas brasileiros. O Semiárido Brasileiro tem baixa altitude e pluviosidade irregular cujas médias atingem $500 \mathrm{~mm}$ de chuvas anuais, mal-distribuídas, e temperaturas que oscilam entre 18 e $40{ }^{\circ} \mathrm{C}$ (Instituto Brasileiro de Geografia e Estatística - IBGE, 2008).

A vegetação da Caatinga é constituída de árvores e arbustos, decíduos durante a seca, que frequentemente contêm espinhos ou acúleos, de cactáceas, de bromeliáceas e de ervas anuais. Esta vegetação desempenha papel socioeconômico na região. No entanto, a cobertura florestal da Caatinga vem sendo dizimada principalmente pela falta de manejo adequado e pelo tipo de exploração adotado (Xavier et al., 2005).

Em função da escassez de dados disponíveis é importante realizar pesquisas nas florestas nativas para melhor manejá-las orientando, consequentemente, as políticas de conservação e manejo adequado.

Na Região Semiárida uma das espécies encontradas com frequência é a jurema-preta (Mimosa tenuiflora (Willd.) Poir.), que tem porte arbustivo, geralmente bifurcada e com galhos baixos, alcançando uma altura média de $4,5 \mathrm{~m}$ com a idade de 5 anos. Possui casca rugosa com fendas longitudinais, é pouco fibrosa, com acúleos no tronco, galhos e ramos. O período normal de floração da espécie se inicia em agosto e se estende até novembro, período este caracterizado pela ausência ou baixa precipitação pluviométrica e que corresponde à seca da Região Semiárida brasileira (Maia, 2004).

$\mathrm{Na}$ Região Nordeste a jurema-preta tem sido explorada para a produção lenha e carvão, em razão do alto poder calorífico (Faria, 1984; Oliveira, 2003; Oliveira et al., 2006). A densidade básica da madeira de jurema-preta aos cinco anos de idade, é de $0,77 \mathrm{~g} \mathrm{~cm}^{-3}$ (Araújo et al., 2004). Além dos empregos como fonte energética, forragem e madeira para construções rurais (cercas e apriscos), em função de sua resistência natural a fungos e cupins xilófagos, sendo comparada à madeira de sabiá (Mimosa caesalpiniifolia), conforme relatado por Paes et al., (2007a; 2007b). Paes et al. (2006a) detectaram que as cascas de jurema-preta possuem $17,74 \%$ de taninos, tendo potencial para indústrias de couro e tanantes.

Para avaliar a produtividade dos povoamentos florestais em volume e massa, as relações dendrométricas são de fundamental importância. Lima et al. (1996) e Campos \& Leite (2002) relataram que, mesmo havendo diferenças biológicas entre os gêneros e as espécies florestais, o diâmetro à altura do peito (DAP) é a variável independente mais utilizada na determinação do volume ou da biomassa, uma vez que é impraticável a cubagem rigorosa de todas as árvores de um povoamento.

De acordo com Scolforo (1993), a cubagem rigorosa pode ser realizada ao se empregar pesagem, imersão ou deslocamento em água, gráfico e por meio de fórmulas matemáticas, como as de Smalian, Huber e Newton.

Lima et al. (1996) relatam o cuidado com a metodologia a ser empregada com as espécies da caatinga e do cerrado, como é o caso da jurema-preta, pois as vegetações de porte arbóreoarbustiva se bifurcam próximo ao solo e contêm vários fustes, nem sempre retos, o que dificulta a estimativa da massa arbórea e do volume.

Em decorrência da importância socioeconômica da vegetação da Região Semiárida brasileira, este estudo teve como objetivo avaliar o volume e a massa de madeira (lenha) e o volume e a massa de casca de jurema-preta (Mimosa tenuiflora (Willd.) Poir.) e sua variação nos períodos seco e chuvoso.

\section{Material e Métodos}

\section{Local de coleta e espécie estudada}

As árvores de jurema-preta (Mimosa tenuiflora (Willd) Poir.), que possuíam boa fitossanidade, foram coletadas em uma mata nativa, na Fazenda Lameirão, de propriedade da Universidade Federal de Campina Grande (UFCG), localizada no Município de Santa Terezinha, Estado da Paraíba (Latitude $\mathrm{S} 7^{\circ}$, Longitude W $37^{\circ} 04^{\prime}$, altitude de 240 metros e clima, segundo a classificação de Köppen, semiárido do tipo Aw' quente úmido, com chuvas de verão ou outono), com média anual das precipitações pluviométricas em torno de $600 \mathrm{~mm}$, distante 385 km de João Pessoa, Capital do Estado.

O solo predominante do local de coleta das árvores é do tipo litólico eutrófico com afloramentos rochosos e a topografia com ondulação e presença de pequenas serras (Superintendência de Administração do Meio Ambiente SUDEMA, 2004; IBGE, 2008). As coletas foram realizadas segundo o ano agrícola, com o intuito de avaliar a influência da fenologia e da estação (seca ou chuvosa) na relação madeira e casca.

A espécie estudada é pioneira, colonizadora de áreas em estado de degradação e de grande potencial como regeneradora de solos erodidos (Maia, 2004). Esta espécie tem floração irregular, tanto no que se refere à periodicidade de floração quanto ao padrão em que ocorre. De acordo com Araújo et al. (2000), ocorre maior floração nos meses de novembro e dezembro enquanto em maio e junho é insignificante. A produção de frutos segue o mesmo padrão da floração; sua coleta é possível durante muitos meses do ano, especialmente entre os meses de julho e janeiro. A germinação de suas sementes ocorre logo no início da estação chuvosa, o número inicial de indivíduos dessa espécie pode chegar aos 40.000 . $\mathrm{ha}^{-1}$ e diminui para menos de 1.000 ha $^{-1}$ nos estádios finais da sucessão (Araújo Filho \& Carvalho, 1996).

\section{Alocações de parcelas e coleta das árvores}

Para a coleta das árvores foram distribuídas, ao acaso, oito parcelas de $20 \times 20 \mathrm{~m}$, onde foram medidos os diâmetros à altura do peito (DAP), tomados a 1,30 metros do solo e a altura total das árvores de jurema-preta. Esta operação teve a finalidade de determinar o diâmetro médio e o volume de madeira presente em cada parcela.

Em cada parcela foram abatidas cinco árvores que possuíam DAP próximo à média da parcela. $\mathrm{O}$ abate das árvores foi realizado em quatro períodos, segundo o período agrícola, sendo abatidas árvores em duas parcelas por período (agosto 
de 2008, dezembro de 2008, abril de 2009 e agosto de 2009), totalizando 40 árvores.

\section{Avaliação das fenofases nos períodos de coleta}

As coletas de dados fenológicos nas parcelas estudadas foram realizadas juntamente com os períodos de coleta dos indivíduos, em que foram avaliados o percentual de folhas verdes e secas e flores e frutos presentes nas plantas, a fim de conhecer o material vegetativo e seu percentual durante a coleta da espécie.

A emissão de folhas foi determinada pela presença de primórdios foliares, em geral de coloração verde-claro a verdeescuro, avermelhados ou violáceos. A presença de folhas secas foi identificada pela coloração marrom-claro a marrom-escuro. A queda de folhas foi embasada na presença de ramos nus e folhas caídas no chão. O período de floração foi até o final do período de antese das flores; o de frutificação, desde a formação visível dos frutos até sua queda.

As porcentagens foram estimadas visualmente e enquadradas em cinco categorias: $\mathrm{I}(0 \%), \operatorname{II}(1-25 \%), \operatorname{III}(26$ - 50\%), IV(51 - 75\%) e V(76 - 100\%) (Fournier, 1974). A identificação taxonômica foi realizada por comparações de exsicatas depositadas no herbário da Universidade Federal de Campina Grande, Centro de Saúde e Tecnologia Rural, Unidade Acadêmica de Ciências Biológicas (UFCG/CSTR/ UACB) e com o auxílio de chaves taxonômicas e de literatura específica.

\section{Análises dendrométricas realizadas}

Como o DAP é de grande importância para o cálculo do volume e da área basal do povoamento, ele foi determinado com base nos valores obtidos das circunferências tomadas a $1,30 \mathrm{~m}$ da altura do solo (CAP), as quais foram medidas com bastante rigor pois quaisquer tipos de erros poderiam comprometer o resultado do trabalho.

Por meio das medidas dendrométricas se estimaram os volumes cilíndrico e cubado das árvores do povoamento e se coletadas informações quanto à altura total ( $\mathrm{H}$ total); altura comercial (H comercial); comprimento de subtoras ( $\mathrm{C}$ toras) de aproximadamente 1,0 m; circunferências (diâmetros) tomadas na base e no topo de cada subtora; e a espessura da casca calculada pela diferença entre as medições das circunferências (diâmetros) com e sem casca tomadas na base e no topo de cada subtora.

\section{Determinação do volume e massa de madeira e casca}

Os troncos das plantas abatidas foram seccionados em toras de aproximadamente $1,0 \mathrm{~m}$ de comprimento, tendo sido utilizadas peças com diâmetro de até $3 \mathrm{~cm}$, considerado como o mínimo empregado na região para fins energéticos.

Foram tomadas medidas da circunferência (diâmetro) na base e no topo das peças, com e sem casca, e seu comprimento com o uso de fita métrica, e o volume calculado pela fórmula de 'Smalian'.

As toras com e sem casca foram empilhadas para determinação do volume de madeira (com e sem casca) em metros estéreo (st) enquanto o volume de casca (em metros cúbicos ou em estéreos) foi obtido pela diferença entre o volume da madeira com e sem casca. As massas de madeira e casca foram obtidas com emprego de balança com capacidade para $100 \mathrm{~kg}$ e precisão de $25 \mathrm{~g}$.

Com os dados obtidos foram verificadas as relações entre os volumes obtidos em estéreo e o volume cubado em metros cúbicos (fórmula de 'Smalian'), o volume e a massa da madeira e o volume e a massa da casca presente nas plantas.

\section{Determinações da densidade básica e da umidade da madeira e da casca}

Visando à determinação da densidade básica e da umidade da madeira (base seca), sem casca, foram selecionadas, nas pilhas, seis peças (duas grossas, duas médias e duas finas). No meio do comprimento das peças obtidas foram retiradas amostras de $\pm 15 \mathrm{~cm}$ de comprimento. As amostras foram pesadas em balança de $0,01 \mathrm{~g}$ de precisão, imersas em água até a saturação e seu volume obtido pelo método de deslocamento em água, conforme metodologia descrita por Vital (1985), e secadas em estufa a $103 \pm 2{ }^{\circ} \mathrm{C}$, até atingirem massas constantes e novamente pesadas.

A densidade básica da madeira foi determinada ao se dividir a massa seca de madeira pelo seu volume saturado, conforme a Norma Brasileira Regulamentadora - NBR 7190, da Associação Brasileira de Normas Técnicas - ABNT (1997).

Para determinação do teor de umidade (base seca) das cascas foi tomada uma amostra representativa do volume de casca $( \pm 100 \mathrm{~g})$. As cascas obtidas foram pesadas e secadas (nas mesmas condições utilizadas para a madeira) e novamente pesadas. A umidade da madeira e da casca foi obtida conforme a norma citada.

\section{Resultados e Discussão}

No primeiro período de coleta (agosto de 2008), as plantas se encontravam em início de período seco, tendo folhas secas ou ausência de folhas e ausência de frutos verdes. Diversos trabalhos citam que espécies com madeira mais densa são mais sensíveis ao estresse hídrico e, consequentemente, perdem suas folhas à medida em que o solo se torna mais seco (Borchert, 1994; Holbrook et al., 1995; Singh \& Kushwaha, 2005). A jurema-preta é considerada uma espécie de alta densidade (Melo et al., 2006) comprovando, assim, a perda das folhas na época de estiagem (Tabela1).

No segundo período (dezembro de 2008), como foi início de período chuvoso, observou-se presença de folhas verdes e jovens. Já no terceiro período, realizado no final do período chuvoso (abril de 2009), observaram-se muitas folhas verdes e presença de botões florais. No quarto e último período avaliado (final de agosto do ano de 2009) fechando assim o

Tabela 1. Fenologia das plantas de jurema-preta (Mimosa tenuiflora) no período de agosto de 2008 a agosto de 2009

\begin{tabular}{cccccc}
\hline \multicolumn{2}{c}{ Período de coleta } & \multicolumn{4}{c}{ Fenologia (\%) } \\
\hline \multirow{2}{*}{ Anos } & Meses & $\begin{array}{c}\text { Folhas } \\
\text { verdes }\end{array}$ & $\begin{array}{c}\text { Folhas } \\
\text { secas }\end{array}$ & $\begin{array}{c}\text { Frutos } \\
\text { maduros }\end{array}$ & Flores \\
\hline \multirow{2}{*}{2008} & Agosto & 30 & 70 & 0 & 0 \\
& Dezembro & 80 & 0 & 0 & 0 \\
\hline \multirow{2}{*}{2009} & Abril & 100 & 0 & 0 & 10 \\
& Agosto & 20 & 20 & 60 & 40 \\
\hline
\end{tabular}


ano agrícola, a vegetação se encontrava novamente seca, com poucas folhas verdes e grande quantidade de frutos maduros (Tabela 1), sendo esta a época de disseminação das sementes da jurema-preta, como citado por Pereira Filho et al. (2005).

A grande presença de jurema-preta nas áreas analisadas pode ser justificada em função de a espécie ser colonizadora de áreas em estado de degradação e do seu potencial como regeneradora de solos erodidos (Maia, 2004; Xavier et al., 2005). Os indivíduos avaliados possuíam DAP entre 5,41 e $7,23 \mathrm{~cm}$, altura total ( $\mathrm{H}$ total) de 4,63 a 5,74m e altura comercial (H comercial) de 3,20 a 5,10m (Tabela 2).

Tabela 2. Valores médios de diâmetro à altura do peito (DAP), altura total (H total) e altura comercial (H comercial) das árvores estudadas

\begin{tabular}{ccccc}
\hline \multicolumn{2}{c}{ Período de coleta } & \multicolumn{3}{c}{ Avaliações } \\
\hline \multirow{2}{*}{ Anos } & Meses & $\begin{array}{c}\text { DAP médio } \\
\text { (cm) }\end{array}$ & $\begin{array}{c}\text { H total } \\
\text { média (m) }\end{array}$ & $\begin{array}{c}\text { H comercial } \\
\text { média (m) }\end{array}$ \\
\hline \multirow{2}{*}{2008} & Agosto & 5,41 & 5,20 & 4,50 \\
& Dezembro & 7,23 & 5,10 & 3,20 \\
\hline \multirow{2}{*}{2009} & Abril & 6,72 & 4,63 & 3,40 \\
& Agosto & 6,42 & 5,74 & 5,10 \\
\hline
\end{tabular}

De acordo com os dados avaliados, quanto maior o DAP maior também a altura total da árvore, indicando indivíduos de maior idade, colhidos nos meses de dezembro de 2008 e abril de 2009, passível de ter ocorrido em função do local de coleta ser aleatório na mata; na Tabela 3 constam os valores médios de volume de madeira e o volume de casca dos períodos avaliados.

O maior volume de madeira foi obtido em agosto de 2009 e o menor em abril de 2009 (Tabela 3). A maior quantidade de madeira e, consequentemente, o menor volume de casca, podem estar relacionados com a qualidade de sitio ou idade das plantas, tendo-se observado que no mês de agosto de 2009 foram coletadas árvores de maior altura comercial, plantas de maior diâmetro no fuste principal e galhos e em abril de 2009 plantas de menor altura total (Tabela 2).

A densidade básica da madeira e o percentual de umidade da madeira e casca para os quatro meses amostrados se encontram na Tabela 4. A densidade da madeira de juremapreta está próxima das obtidas por Zakia et al. (1990), para a região do Seridó do Rio Grande do Norte, que foi de 0,86 g. $\mathrm{cm}^{-3}$ e Araujo et al. (2007), para duas regiões do Estado da Paraíba, que obtiveram valor de $0,82 \mathrm{~g} . \mathrm{cm}^{-3}$, superior à obtida por Araujo et al., 2004, para plantas provenientes de um experimento com cinco anos, que foi de $0,77 \mathrm{~g} . \mathrm{cm}^{-3}$, e inferior à obtida por Oliveira et al. (2006) que obtiveram $0,91 \mathrm{~g} . \mathrm{cm}^{-3}$; tais diferenças podem ser explicadas pela idade das plantas e, ou, qualidade, de sítio em que as mesmas florescem.

A madeira e a casca de jurema-preta tiveram, nos meses de dezembro de 2008 (início do período chuvoso) e abril de 2009
Tabela 4. Densidade básica e teor de umidade da madeira e da casca em coletas realizadas no período de agosto de 2008 a agosto de 2009

\begin{tabular}{cccccc}
\hline \multicolumn{2}{c}{ Período de coleta } & Densidade básica & \multicolumn{2}{c}{ Teor de umidade (\%) } \\
\cline { 1 - 1 } \cline { 5 - 6 } Anos & Meses & madeira $\left(\mathbf{g ~ c m}^{-3}\right)$ & Madeira & Casca \\
\hline \multirow{2}{*}{2008} & Agosto & 0,82 & 37,54 & 47,62 \\
& Dezembro & 0,84 & 44,18 & 90,60 \\
\hline \multirow{2}{*}{2009} & Abril & 0,81 & 45,44 & 83,50 \\
& Agosto & 0,85 & 37,97 & 67,22 \\
\hline
\end{tabular}

(final de período chuvoso), maior percentual de umidade em relação aos meses de agosto de 2008 e agosto de 2009 (início de período seco) que possuíram menor teor de umidade. $\mathrm{O}$ alto teor de umidade do material colhido nos meses de dezembro e abril era esperado pois havia a ocorrência de chuvas aumentando, assim, o teor de umidade presente no solo e nos vegetais.

$\mathrm{Na}$ Tabela 5 é possível observar os valores médios encontrados para massa de madeira sem casca e massa de casca nas coletas realizadas no período de agosto de 2008 a agosto de 2009, em base seca.

Tabela 5. Valores médios encontrados para massa de madeira sem casca e de casca em coletas realizadas no período agosto de 2008 a agosto de 2009 em base seca

\begin{tabular}{cccccc}
\hline \multicolumn{2}{c}{ Período de coleta } & \multicolumn{4}{c}{ Avaliações } \\
\hline \multirow{2}{*}{ Ano } & \multirow{2}{*}{ Mês } & \multicolumn{2}{c}{ Massa de madeira } & \multicolumn{2}{c}{ Massa de casca } \\
\cline { 3 - 6 } & & $\mathbf{( k g )}$ & $\mathbf{( \% )}$ & $\mathbf{( k g )}$ & $\mathbf{( \% )}$ \\
\hline \multirow{2}{*}{2008} & Agosto & 63,47 & 71,68 & 25,08 & 28,32 \\
& Dezembro & 101,64 & 70,01 & 43,54 & 29,99 \\
\hline \multirow{2}{*}{2009} & Abril & 57,19 & 64,70 & 31,20 & 35,30 \\
& Agosto & 127,50 & 76,21 & 39,38 & 23,79 \\
\hline
\end{tabular}

Observou-se que quanto menor a massa de madeira maior a de casca. Alguns autores pesquisaram a massa de madeira de jurema-preta, como Araújo et al. (2004) que encontraram o total de $631,3 \mathrm{~kg}$ de massa úmida de madeira de jurema-preta, com casca, para 30 árvores de 5 anos de idade. A diferença entre o valor encontrado por Araújo et al. (2004) e o obtido nesta pesquisa $(349,80 \mathrm{~kg})$ é consequência da umidade da madeira que, no caso desta pesquisa, foi de $41,28 \%$ da massa de casca.

Com relação à massa de casca $(139,20 \mathrm{~kg})$ que correspondeu a $29,35 \%$ da massa total de madeira, é uma informação de importância uma vez que Paes et al. (2006a) encontraram $17,74 \%$ de taninos condensados nas cascas de jurema-preta, que tiveram boas características no curtimento de peles caprinas (Paes et al., 2006b; Lima, 2011).

\section{Conclusões}

Os meses de dezembro de 2008 e abril de 2009 proporcionaram maior percentual de folhas verdes, em consequência do período chuvoso na região.

Tabela 3. Volumes de madeira e casca de jurema-preta em coletas realizadas nos períodos avaliados

\begin{tabular}{|c|c|c|c|c|c|c|}
\hline \multicolumn{2}{|c|}{ Período de Coleta } & \multicolumn{5}{|c|}{ Avaliações } \\
\hline \multirow[t]{2}{*}{ Anos } & \multirow[t]{2}{*}{ Meses } & $\begin{array}{c}\text { Volume madeira } \\
\text { com casca }\end{array}$ & $\begin{array}{c}\text { Volume madeira } \\
\text { sem casca }\end{array}$ & $\begin{array}{l}\text { Volume } \\
\text { casca }\end{array}$ & $\begin{array}{l}\text { Volume } \\
\text { madeira }\end{array}$ & $\begin{array}{c}\text { Volume } \\
\text { casca }\end{array}$ \\
\hline & & & $\left(\mathrm{m}^{3}\right)$ & & & \\
\hline \multirow{2}{*}{2008} & Agosto & 0,1080 & 0,0774 & 0,0306 & 71,68 & 28,32 \\
\hline & Dezembro & 0,1728 & 0,1210 & 0,0518 & 70,01 & 29,99 \\
\hline \multirow{2}{*}{2009} & Abril & 0,1090 & 0,0706 & 0,0384 & 64,71 & 35,29 \\
\hline & Agosto & 0,2362 & 0,1800 & 0,0562 & 76,21 & 23,79 \\
\hline
\end{tabular}


A época de frutificação é definida como final de período chuvoso, tendo as plantas grande percentual de frutos.

$\mathrm{O}$ volume e a massa de madeira não estão relacionados com o volume nem com a massa de casca.

Os meses de dezembro de 2008 (início do período chuvoso) e abril de 2009 (final de período chuvoso) proporcionaram maior teor de umidade na madeira e na casca de jurema preta.

No mês de agosto de 2009 foram observadas maior massa de madeira sem casca, menor percentual em casca de jurema preta e maior densidade da madeira das plantas colhidas.

\section{Literatura Citada}

Araújo Filho, J. A.; Carvalho, F. C. Desenvolvimento sustentado da Caatinga. In: Alvarez, V. H.; Fontes, L. E. F. Fontes, M. P. (Eds.). O solo nos grandes domínios morfoclimáticos do Brasil e o desenvolvimento sustentado. Viçosa: SBCS/UFV/DPS, p. 125-133, 1996.

Araújo, L. V. C.; Leite, J. A. N.; Arriel, E. F.; Bakke, O. A. Aspectos fenológicos de uma população de jurema preta (Mimosa hostilis Benth.) sem acúleos. In: Congresso e Exposição Internacional sobre Floresta, 6., 2000, Porto Seguro. Anais... Porto Seguro: Forest 2000, 2000. p. 18-19.

Araújo, L. V. C.; Paulo, M. C. S.; Paes. J. B. Características dendrométricas e densidade básica da jurema-preta (Mimosa tenuiflora (Willd.) Poir.) de duas regiões do Estado da Paraíba. Caatinga, v.20, n.1, p.89-96, 2007. $<$ http://periodicos.ufersa.edu.br/revistas/index.php/ sistema/article/view/423/88>. 05 Ago. 2013.

Araújo, L. V. C.; Leite, J. A. N.; Paes, J. B. Estimativa da produção de biomassa de um povoamento de jurema-preta (Mimosa tenuiflora (Willd.) Poiret. com cinco anos de idade. Biomassa \& Energia, v. 1, n. 4, p. 347-352, 2004. <http://www.renabio. org.br/04-B\&E-v1-n4-2004-p347-352.pdf $>.05$ Ago. 2013.

Associação Brasileira de Normas Técnicas. NBR 7190: Projeto de estruturas de madeira. Anexo B - Determinação das propriedades das madeiras para projeto de estruturas. Rio de Janeiro, 1997. 107p.

Borchert, R. Soil and stem water storage determine phenology and distribution of tropical dry forest trees. Ecology, v.75, n.5, p.1437-1449, 1994. <http://dx.doi. org/10.2307/1937467>. 05 Ago. 2013.

Campos, J. C. C.; Leite, H. G. Mensuração florestal: Perguntas e respostas. Viçosa: UFV, 2002. 407p.

Faria, W. L. F. A jurema preta (Mimosa hostilis Benth.) como fonte energética do Semi-Árido do Nordeste - Carvão. Curitiba: Universidade Federal do Paraná, 1984. 113p. Dissertação Mestrado. <http://dspace.c3sl. ufpr.br/dspace/bitstream/handle/1884/25171/D\%20 -\%20FARIA $\% 2 \mathrm{c} \% 20$ WASHINGTON $\% 20$ LUIZ $\% 20$ FONSECA.pdf?sequence=1>. 05 Ago. 2013.

Fournier, L. A. Un método cuantitativo para la medición de características fenológicas en árboles. Turrialba, v. 24, n.4, p.422-423, 1974.

Holbrook, N. M.; Whitbeck, J. L.; Mooney, H. A. Drought responses of neotropical dry forest trees. In: Bullock, S.H.; Mooney, H.A.; Medina E. (Eds.). Seasonally dry tropical forests. Cambridge: Cambridge University Press, 1995. p. 243-276.
Instituto Brasileiro de Geografia e Estatística - IBGE. Paraíba: Santa Teresinha. <http://www.cidades.ibge.gov.br/xtras/ perfil.php?lang $=\& \operatorname{codmun}=251380 \&$ search $=$ paraiba $\mid$ san ta-teresinha>. 17 Jul. 2008.

Lima, C. R. Potencialidade dos extratos tânicos das espécies angico vermelho, jurema preta e jurema-vermelha no curtimento de peles caprinas. Campina Grande: Universidade Federal de Campina Grande, 2011. 61p. Tese Doutorado. <http://www.recursosnaturaisufcg.org/ downloads/carlosrobertodelima.pdf $>.12$ Ago. 2013.

Lima, P. C. F.; Oliveira, E. B.; Machado, S. A. Equações para estimativa de biomassa de espécies de Prosopis no Semiárido Brasileiro. Boletim de Pesquisa Florestal, n.32/33, p.67-79, 1996. <http://www.cnpf.embrapa.br/publica/ boletim/boletarqv/boletim32_33/plima.pdf>. 12 Ago. 2013.

Maia, G. N. Caatinga: árvores e arbustos e suas utilidades. São Paulo: D\&Z, 2004. 413p.

Melo, R. R.; Paes, J. B.; Lima, C. R.; Ferreira, A. G. Estudo da variação radial da densidade básica de sete madeiras do semi-árido. Revista Científica Eletrônica de Engenharia Florestal, v. 4, n.7, p.1-8, 2006. <http://www.revista.inf.br/ florestal07/pages/artigos/artigo07.pdf >. 05 Ago. 2013.

Oliveira, E. Características anatômicas, químicas e térmicas da madeira de três espécies de maior ocorrência no Semi-Árido Nordestino. Viçosa: Universidade Federal de Viçosa, 2003. 122p. Tese Doutorado. $\quad<\mathrm{http}$ ://www.bibliotecaflorestal.ufv. $\mathrm{br} / \mathrm{bitstream} / \mathrm{h}$ andle/123456789/352/117600_c. pdf? sequence=2>. 17 Ago. 2013.

Oliveira, E.; Vital, B. R.; Pimenta, A. S.; Della Lucia, R. M; Ladeira, A. M. M; Carneiro, A. C. O. Estrutura anatômica da madeira e qualidade do carvão de Mimosa tenuiflora (Willd.) Poir. Revista Árvore, v.30, n.2, p.311-318, 2006. $<$ http://dx.doi.org/10.1590/S0100-67622006000200018>.

Paes, J. B.; Marinho, I. V.; Lima, R. A.; Lima, C. R.; Azevêdo, T. K. B. Viabilidade técnica dos taninos de quatro espécies florestais de ocorrência no semi-árido brasileiro no curtimento de peles. Ciência Florestal, v.16, n.4, p.453462, 2006b. <http://cascavel.ufsm.br/revistas/ojs-2.2.2/ index.php/cienciaflorestal/article/view/1927/1169>. 05 Ago. 2013.

Paes, J. B.; Diniz, C. E. F.; Marinho, I. V.; Lima, C. R. Avaliação do potencial tanífero de seis espécies florestais de ocorrência no semi-árido brasileiro. Cerne, v.12, n.3, p.232-238, 2006a. <http://www.dcf.ufla.br/cerne/ artigos/10-02-20094298v12_n3_artigo\%2004.pdf>. 17 Ago. 2013.

Paes, J. B.; Melo, R. R.; Lima, C. R. Resistência natural de madeiras a fungos xilófagos em condições de laboratório. Revista de Ciências Agrárias, n.47, p.199-210, 2007 a. $<$ http://www.ufra.edu.br/editora/revista_47/REVISTA\%20 47_artigo\%2014.pdf >. 17 Ago. 2013.

Paes, J. B.; Melo, R. R.; Lima, C. R.; Oliveira, E. Resistência natural de sete madeiras ao cupim subterrâneo (Nasutitermes corniger Motsch.) em ensaio de preferência alimentar. Revista Brasileira de Ciências Agrárias, v.2, n.1, p.57-62, 2007b. <http://agraria.pro.br/sistema/index.php?j ournal $=$ agraria\&page $=$ article $\& o p=$ viewFile $\&$ path []$=42 \& p$ ath[] $=70>.05$ Ago. 2013. 
Pereira Filho, J. M.; Vieira, E. L.; Kamalak, A.; Silva, A. M. A.; Cezar, M. F. E.; Beelen, P. M. G. Correlação entre o teor de tanino e a degradabilidade ruminal da matéria seca e proteína bruta do feno de jurema-preta (Mimosa tenuiflora (Wild.) Poiret) tratada com hidróxido de sódio. Livestock Research for Rural Development, v.17, n.8, art.91, 2005. $<$ http://www.lrrd.org/lrrd17/8/pere17091.htm>. 12 Ago. 2013.

Scolforo, J. R. S. Mensuração Florestal I: medição de árvores e povoamentos florestais. Lavras: UFLA/FAEP, 1993. 146p.

Singh, K. P.; Kushwaha, C. P. Emerging paradigms of tree phenology in dry tropics. Current Science, v.89, n.6, p.964975, 2005. <http://www.agroparistech.fr/geeft/Downloads/ Training/TropEcol/Bib_exercise/2.2b.pdf>. 05 Ago. 2013.
Superintendência de Administração do Meio Ambiente SUDEMA. Atualização do diagnóstico florestal do Estado da Paraíba. João Pessoa: SUDEMA, 2004. 268p.

Vital, B.R. Métodos de determinação da densidade da madeira. Viçosa, 1984. 21 p. (Boletim Técnico, 1).

Xavier, E. P. L.; Paes, J. B.; Lira Filho, J. A. Potencial madeireiro de duas microrregiões do Estado da Paraíba. Biomassa \& Energia, v.2, n.2, p.103-112, 2005. <http:// www.renabio.org.br/02-BE-011-XavierEP-2005-103-102. pdf>. 12 Ago. 2013.

Zakia, M. J. B.; Parein, F. G.; Rieellhaupt, E. Equações de peso e volume para oito espécies lenhosa nativas do SeridóRN. Natal: PNUD/FAO/BRA/87/007, 1990. 5p. (Circular Técnica, 9). 